\title{
PIBID como uma epistemologia da formação de professores no cotidiano escolar
}

Fabrício Oliveira da Silva'

\section{RESUMO}

O artigo analisa como o Programa Institucional de Bolsas de Iniciação à Docência - PIBID se coloca como uma epistemologia de formação de professores que considera o cotidiano escolar como espaço de produção de experiências do ser professor. Tem como principal objetivo compreender como o PIBID possibilita a vivência do chão escolar e como esta constitui-se em experiências formativas do ser professor. A pesquisa desenvolveu-se a partir de abordagem (auto)biográfica, que é de natureza qualitativa e caracteriza-se por ser um método que possibilita ao sujeito que narra construir e revelar sentidos para o vivido, para suas experiências, logo para o seu processo de formação. Como dispositivos de pesquisa, foram utilizados memorial de formação e entrevistas narrativas de três licenciandos do curso de Letras de uma instituição pública de Ensino Superior do Estado da Bahia. O estudo revelou que no PIBID o conceito de formação é concebido epistemologicamente como um movimento reflexivo de compreensão da profissão docente, analisado a partir da inserção dos licenciandos no cotidiano da escola. Viver e conhecer o chão da escola significa poder produzir experiências da docência no contexto real do exercício profissional.

Palavras-chave: PIBID. Formação de professores. Cotidiano Escolar

\section{PIBID as an epistemology of teacher training in the everyday school}

\section{ABSTRACT}

The article analyzes how the Institutional Program of Initiatives to Teaching - PIBID is an epistemology of teacher training that considers

1 Doutor em Educação pelo Programa de Pós-Graduação em Educação e Contemporaneidade - UNEB. Professor Assistente da Universidade do Estado da Bahia, Campus XVI - Irecê. Membro do Grupo de Pesquisa - Docência, Narrativas e Diversidade na Educação Básica DIVERSO, vinculado ao Programa de Pesquisa e Pós-Graduação - PPGEduC - UNEB. E-mail: faolis@ig.com.br 
the daily school life as a space for the production of experiences of being a teacher. Its main objective is to understand how the PIBID makes possible the experience of the school ground and how it is constituted in formative experiences of being a teacher. The research developed from a (self) biographical approach, which is qualitative in nature and is characterized by being a method that allows the subject who narrates to construct and reveal meanings for the lived, for his experiences, soon for his process training. As research devices, training memo and narrative interviews were used of three graduates of the course of Literature of a public institution of Higher Education of the State of Bahia. The study revealed that in the PIBID the concept of formation is epistemologically conceived as a reflexive movement of understanding of the teaching profession, analyzed from the insertion of the graduates in the daily life of the school. Living and knowing the school floor means being able to produce experiences of teaching in the real context of professional practice.

Keywords: PIBID Teacher training. Everyday School

\section{PIBID como una epistemología de la formación de profesores en el cotidiano escolar}

\section{RESUMEN}

El artículo analiza cómo el Programa Institucional de Becas de Iniciación a la Docencia - PIBID se plantea como una epistemología de formación de profesores que considera el cotidiano escolar como espacio de producción de experiencias del ser profesor. Tiene como principal objetivo comprender cómo el PIBID posibilita la vivencia del suelo escolar y cómo ésta se constituye en experiencias formativas del ser profesor. La investigación se desarrolló a partir de un enfoque (auto) biográfico, que es de naturaleza cualitativa y se caracteriza por ser un método que posibilita al sujeto que narra construir y revelar sentidos para lo vivido, para sus experiencias, luego para su proceso de formación. Como instrumentos de investigación, fueron utilizados memorial de formación y entrevistas narrativas de tres licenciandos del curso de Letras de una institución pública de Enseñanza Superior del Estado de Bahía. El estudio reveló que en el PIBID el concepto de formación es concebido epistemológicamente como un movimiento reflexivo de 
comprensión de la profesión docente, analizado a partir de la inserción de los licenciandos en el cotidiano de la escuela. Vivir y conocer el suelo de la escuela significa poder producir experiencias de la docencia en el contexto real del ejercicio profesional.

Palavras clave: PIBID. Formación de profesores. Cotidiano Escolar.

\section{Introdução}

Este artigo analisa como o $\mathrm{PIBID}^{2}$ se constitui uma epistemologia de formação de professores, para além do entendimento de ser o Programa apenas um espaço formativo. Neste sentido, buscamos analisar como a formação inicial de licenciandos em Letras acontece entremeada por uma epistemologia da aprendizagem experiencial, entendendo a iniciação à docência no PIBID como um processo que se constitui pelas vivências logradas no cotidiano escolar, logo pelo conhecimento epistemológico da tessitura do fazer docente, que se caracteriza pelo exercício reflexivo e identitário do que significa ser professor.

Assim, O PIBID se apresenta como um programa de formação de professores que inicialmente estabelece uma crítica ao modelo epistemológico de formação nos cursos de licenciatura, ponderando sobre algumas questões, tais como: i) A formação do professor da Educação Básica não se faz na realidade da escola, pois os licenciandos só se inserem pontualmente na escola, como no caso dos estágios; ii) A formação dos licenciandos nem sempre considera os diferentes tempos e ritmos de aprendizagem do sujeito; iii) Quem ensina deve também aprender o que ensinar na relação com quem se ensina. Em licenciaturas, fora dos contextos possibilitados pelo Programa, essa não tem sido a tônica, pois o cotidiano escolar, lugar das relações e de desenvolvimento das experiências, não é experienciado pelos licenciandos.

O estudo em tela é um recorte da pesquisa desenvolvida com três bolsistas do PIBID do curso de Letras de uma instituição pública de Ensino Superior do Estado da Bahia, utilizando as narrativas de formação

2 Conforme definição e caracterização da CAPES, o PIBID (Programa Institucional de Bolsas de Iniciação à Docência) é uma iniciativa para o aperfeiçoamento e a valorização da formação de professores para a Educação Básica. O programa concede bolsas a alunos de licenciatura, participantes de projetos de iniciação à docência desenvolvidos por Instituições de Educação Superior (IES), em parceria com escolas de Educação Básica da rede pública de ensino. Os projetos visam promover a inserção dos estudantes no contexto das escolas públicas, desde o início da sua formação acadêmica, para que desenvolvam atividades didático-pedagógicas, sob orientação de um docente da licenciatura e de um professor da escola. 
dos bolsistas de iniciação à docência para compreender como o processo de iniciação à docência se efetiva a partir das experiências formativas tecidas no chão da escola. Neste recorte, analisamos as narrativas de três licenciandos, com o objetivo de entender as seguintes questões: Como o cotidiano escolar é vivenciado na formação de bolsistas no PIBID? Quais sentidos sobre o ser professor são produzidos na formação inicial vivenciada pelo PIBID? Como o bolsista do PIBID vai construindo o conhecimento sobre a docência?

Como aporte metodológico, optamos por desenvolver uma pesquisa que nos permitisse refletir sobre tais questões, trazendo para a centralidade do debate o que refletem os próprios sujeitos ao abordarem sobre suas experiências formativas no PIBID. Desse modo, decidimos por uma pesquisa de base qualitativa, com ancoragem na perspectiva metodológica da (auto)biografia. Utilizamos dois dispositivos para a recolha das informações: as entrevistas narrativas e os memoriais de formação. Isso se justifica pela possibilidade de ouvirmos o sujeito narrar suas experiências formativas no Programa, bem como escrever sobre tais experiências. Assim, utilizamos tanto os escritos como a fala dos próprios sujeitos para compreendermos como a aprendizagem da docência vai se constituindo no campo experiencial tecido no cotidiano escolar.

A abordagem (auto)biográfica está diretamente relacionada a uma concepção de educação construída ao longo da vida de um sujeito, valorizando o seu processo de formação e os sentidos que se constroem pelas trajetórias de formação. Assim, as "narrativas (auto)biográficas não são, apenas, descrições ou interpretações de acontecimentos pessoais, mas constituem uma ação social por meio da qual o indivíduo retotaliza sua trajetória de vida e sua interação com o social" (FERRAROTTI, 1988, p. 27).

Consideramos, portanto, a perspectiva dos estudos (auto)biográficos extremamente pertinente ao desenvolvimento desta pesquisa, por ser esse um método que se propõe a analisar as histórias de vida e de formação, centrando a investigação nos sentidos que o próprio sujeito imprime ao ato de se tornar educador. Neste movimento, que é demarcado pela sua história de vida, aqui de formação, as experiências do sujeito consolidam o desenvolvimento de reflexões sobre a aprendizagem da docência, que se internalizam, para a construção de sua identidade docente. Logo, nossa inclinação por essa abordagem de pesquisa passou a se efetivar, tendo em vista a perspectiva de estudar as trajetórias de formação dos estudantes no PIBID e a natureza qualita- 
tiva da pesquisa (auto)biográfica, em que o sujeito narra a sua história formativa, focalizando a subjetividade do processo de formação e de produção, ainda que inicial, da identidade docente. Isso pode ser visto na compreensão de Karine ${ }^{3}$, quando expressa o lugar da narrativa nesta pesquisa. Assim ela nos diz:A partir das narrativas sobre esse nosso processo de formação, bem como nosso histórico de vida até chegar na instituição, para cursar um curso de Licenciatura, me possibilitou perceber que, de alguma forma, a nossa formação passa por esses momentos de vida, por refletirem de alguma forma em nossa atuação. Na universidade, sempre escrevi em terceira pessoa, inclusive acredito que comecei esse memorial nessa perspectiva, mas a possibilidade de olhar para nosso interior, para nossas experiências de vida e de PIBID, ouvir de alguns colegas as narrativas desse processo foi muito bom (Karine, memorial de formação, 2016). A narrativa, portanto, é o elemento de apropriação do sujeito, para que, em primeira pessoa, possa revelar os sentidos de sua trajetória de formação. É desse lugar, de poder narrar e ser autor de sua própria história, que a bolsista faz uma análise de si, desenvolvendo aprendizagens sobre sua formação experiencial na vida e no Programa. A narrativa, segundo ela, a faz olhar para o seu interior e a faz compreender quem ela é e como pensa, sobretudo quando considera ser muito bom ouvir as narrativas de seus colegas.

Evidenciar a aproximação entre as escritas de si e a aprendizagem da docência no PIBID constitui, então, uma possibilidade de aplicação dos pressupostos metodológicos da pesquisa (auto)biográfica, que, segundo Nóvoa e Finger (2010), introduziu uma revolução na concepção tradicional de estudo da formação de professores. A história de vida dos sujeitos é atravessada pelos processos formativos que estes vivenciam, dado que não se pode separar o vivido socialmente do contexto de formação que se dá em uma especificidade, nos percursos, da vida do sujeito. Isto posto, a pesquisa (auto)biográfica favorece a compreensão que se tem da história de vida, em uma perspectiva hermenêutica, concebida por um sistema de interpretação e de construção de sentidos, que articula e faz significar os acontecimentos formativos da vida, como elementos que se organizam no interior de um todo.

3 Apesar de optar pela abordagem (auto)biográfica, em que a centralidade está nos sentidos produzidos pelo próprio sujeito, que é tomado como autor de sua própria história de vida e formação, os nomes aqui utilizados são fictícios, em atendimento ao sugerido pelo Comitê de Ética em Pesquisa. Os nomes foram escolhidos pelos sujeitos colaboradores. 


\section{Histórico e objetivo do PIBID}

O PIBID foi lançado, em sua primeira versão, em dezembro de 2007, por meio de um edital que tinha como principal objetivo atender as demandas de formação de licenciandos, nas áreas de Ciências Exatas e Naturais. A justificativa para o desenvolvimento do Programa, nessas duas áreas, deu-se por conta, segundo o Censo escolar INEP/ MEC do mesmo ano, de uma baixa procura pelos cursos de licenciatura, principalmente nas áreas de Química, Física, Matemática e Biologia. A perspectiva inicial do Ministério de Educação com o Programa era atrair os jovens para que cursassem licenciatura e tivessem nela um adequado processo formativo. A partir de 2009, o Ministério fez progredir o Programa, publicando editais em todas as áreas do conhecimento.

No cenário de políticas públicas de fomento à educação, o PIBID constitui parte das ações do governo federal, que tiveram início em 2007, tendo em vista o desenvolvimento da Educação. Assim, o Programa integra o conjunto de reformas iniciadas naquele ano, com a promulgação de Diretrizes Nacionais para a Formação, em nível superior, de professores para a Educação Básica (Parecer CNE/CP nº 009/2001 e Resolução CNE/CP no 1/2002). Nesta direção, o PIBID surge de um conjunto de objetivos que primavam por combater os problemas centrais relacionados à formação e à valorização dos professores da Educação Básica, em todo o território nacional.

Em julho de 2013, houve a publicação da Portaria 96, com o propósito de atualizar e aperfeiçoar as normas do Programa, além de favorecer a valorização do magistério pela elevação da qualidade da formação inicial dos professores. Destacamos o fato de que, segundo a referida portaria, essa formação deveria ocorrer, inicialmente, por uma boa articulação entre teoria e prática, entre a Educação Superior e a Básica, isto é, entre a universidade e a escola básica. Como princípio norteador do Programa está o processo de formação, que passa a ser concebido pela inserção do licenciando na realidade escolar, em sua dinâmica organizativa, em um tempo e espaço que a universidade pouco alcançava. A valorização do magistério, nesta condição, passa pela perspectiva de se qualificar o docente para que o exercício do magistério atenda às reais necessidades da escola, com vistas à elevação dos índices de qualidade do ensino por ela ofertado. 
A dicotomia existente na relação universidade e escola básica tem seus fundamentos no PIBID, pela intersecção de teoria e prática, a partir da ideia de que a formação de professores e o desenvolvimento da docência precisam considerar os contextos "práticos", reais, da escola. Assim, na educação, o conhecimento teórico passa a ter valor, quando a possibilidade de sua aplicação se centra na condição prática que o sujeito tem de aplicá-lo e torná-lo significativo, sobretudo para o estudante. No Programa, a relação entre universidade e escola básica parece centrar-se numa perspectiva que considera o papel interseccional entre teoria e da prática educativa desenvolvida, também na universidade, mas vivenciada no contexto real da escola. O PIBID, mesmo sendo apenas um Programa, figura como uma possibilidade de articulação entre teoria e prática, aqui vistas como complementares e não como elementos segregados, uma vez que a vivência no espaço escolar passa a figurar como uma realidade de observação e de desenvolvimento de experiências que emergem das atividades práticas que o licenciando poderá empregar na escola.

Para Silva (2017), a realidade escolar, entendida na metáfora do "chão da escola", torna-se um espaço por meio do qual os licenciandos, no PIBID, passam a vivenciar e compreender a docência no contexto prático onde ela ocorre. A consequência disso é que os participantes do Programa, colaboradores deste estudo, em específico, possibilitam reflexões na universidade, trazendo, em alguns contextos, o debate que permeia a relação teórico-prática, para o interior da academia, e fazendo aflorar, ainda que de modo pontual e contextual, em alguns poucos componentes curriculares, as discussões da formação de professores sob a perspectiva da vivência na/da profissão. O problema é que o PIBID não é uma política de formação direcionada a todos. Limita-se ao status de um Programa que, em tal condição, não atende a totalidade de estudantes da licenciatura, além de voltar-se, também, para outros objetivos, como o de oferecer bolsas para a permanência do estudante no curso de graduação. Isso tem gerado críticas ao PIBID, por entendê-lo no lugar de um simples Programa que passa, em alguns contextos, a ser considerado atrativo, não pela aprendizagem que promove, mas pela condição de ofertar uma bolsa aos seus participantes.

Mesmo sendo apenas um programa, o PIBID é concebido pela política governamental na condição de integrar ações de melhoria da educação nacional, constituindo-se, assim, em um importante passo para pensar a formação inicial para a docência no âmbito das univer- 
sidades brasileiras. O Programa foi pensado e desenhado pelo fato de haver um notório distanciamento entre a universidade e a escola, no que tange à compreensão acadêmica dos reais problemas e dilemas enfrentados pela Educação Básica. Os objetivos do Programa visam, entre outras coisas, potencializar a formação inicial de professores da Educação Básica, considerando que esta formação precisa acontecer também na escola e em seu cotidiano. Nesta direção, o Programa ganha força, na medida em que se propõe a realizar uma aproximação da universidade com a escola básica, não pela condição de que a universidade se proponha a ensinar a escola a realizar o seu trabalho, mas como uma forma de estabelecer uma parceria que dê a ambas condições para a produção de um diálogo profícuo sobre como desenvolver uma formação para o exercício da docência que agregue qualidade e compromisso social.

Em 2007, quando o MEC propõe a criação, em 2009, 2012 e 2014, a ampliação e a manutenção do PIBID, parte do pressuposto de que, no processo de formação em licenciatura, é preciso haver a inserção desse sujeito, que se forma no cenário de atuação profissional, na escola básica. $\mathrm{O}$ argumento do Ministério de Educação centra-se na lógica de que é preciso que o licenciando conheça o chão da escola, vivencie seus conflitos e dilemas e neles construa os saberes necessários ao exercício da docência. Mas, de fato, não é somente na escola, que se aprende a ser professor. Nesse cenário, a universidade continua sendo a instituição formadora por excelência, pois é nesta instituição que a licenciatura é realizada, cujo papel central é formar o professor. A diferença, entretanto, é que há, por parte de alguns que se licenciam, a condição de, ainda no processo de formação, dialogar com seus professores, a partir das experiências constituídas no PIBID, por sua inserção no cotidiano escolar, tendo em vista compreender as práticas do ensino escolar. Além disso, conta com tempo e oportunidade de fazê-las e refazê-las, estando num movimento formativo e dialógico com os docentes da universidade. Isso implica dizer que, ao se licenciar, a escola não será um elemento estranho e desconhecido para o futuro professor.

No entanto, o PIBID é um Programa que não atende a todos os estudantes da licenciatura. Apenas alguns têm a oportunidade de viver as experiências formativas e de se inserir no cotidiano da profissão, como um meio de também ampliar sua compreensão sobre a docência. Isso já é por si só suficiente para entendermos que o PIBID não se constitui como uma ação formativa garantida a todos os estudantes, condição 
que põe em xeque a ideia de se pensar o Programa como um espaço amplo de formação inicial de professores. Mas, ao se analisar o contexto formativo daqueles que participam do PIBID, há de se observá-lo com vistas a compreender as contribuições do Programa para o processo formativo de professores. É neste contexto de participantes que buscamos entender como o PIBID se constitui uma epistemologia formativa que contribui para o desenvolvimento da aprendizagem experiencial da docência.

Deste modo, entender a sala de aula, o funcionamento dos mecanismos que os professores desenvolvem para constituir o seu trabaIho na escola, tudo isso é tomado como elemento de significação para a compreensão do papel do Programa, diante da trajetória formativa do bolsista Jonas. É no contexto da escola, nos meandros do desenvolvimento das atividades educativas, que ele se vê num processo identitário, concluindo que o PIBID possibilitou o seu acesso e a identificação com a profissão. Assim ele nos relata, em seu memorial:

\begin{abstract}
[...] o PIBID passou a se configurar como o principal incentivador da minha formação e do desenvolvimento das atividades educativas, que foram para mim o processo de produção da identidade docente. Primeiro porque as aprendizagens da docência se ampliaram, se tornaram mais possíveis, ou seja, houve uma ressignificação da ideia que eu tinha sobre a profissão docente. Segundo, porque foi a partir daquele momento que eu comecei a entender a sala de aula e seu funcionamento. (Jonas, memorial de formação, 2016)
\end{abstract}

Nóvoa (2013, p. 203), ao tratar das proposições para a formação docente, enfatiza e defende a ideia de que "as propostas teóricas só fazem sentido se forem construídas dentro da profissão, se completarem a necessidade de um professor actuante no espaço de sala de aula". A referência aqui posta trata da dimensão que considera o professor licenciado em ação no magistério, e que supostamente tem condições de, estando na profissão, pensar sobre a mesma.

Trata-se, portanto, de construir, no presente, o futuro da docência. Para os licenciandos, isso implica o reconhecimento de que o futuro, ou seja, a entrada na profissão na condição de docentes licenciados deve ser constituída através de possibilidades criadas/inscritas no presente, logo na formação. Como nos diz Oliveira (2010) o “[...] futuro a ser construído, então, só pode sê-lo a partir do aproveitamento de possibili- 
dades criadas/inscritas no presente e, [...]" (OLIVEIRA, 2010, p. 31). Nessa reflexão, é possível observar que as experiências do presente, inscritas e produzidas no contexto do cotidiano do PIBID, constroem possibilidades de elaboração de um futuro que seja significado a partir das experiências constituídas no presente.

\section{Cotidiano escolar: uma alquimia formativa no PIBID}

O cotidiano institui-se, assim, em uma presentificação por meio da qual as práticas comuns e as experiências particulares dos sujeitos emergem como forma de tornar factível o entendimento do vivido, na condição de um espaço e um tempo de produção da existência e dos conhecimentos, de práticas e valores que se fazem no dia a dia e que nele ganham novos sentidos, sobretudo nas trajetórias de vida e formação. Nesta direção, a ideia de cotidiano, em Certeau (1994) permite-nos inferir que há diversas maneiras de fazer a vida cotidiana acontecer, o que, por si só, já ratifica a concepção que adotamos de que a vida cotidiana não é apenas o lugar de repetição e de reprodução de uma "estrutura social" complexa e abstrata. O cotidiano é também aquilo que nos é dado a cada dia, sendo um presente que se presentifica em um ineditismo, pois as práticas não são iguais, ainda que sejam comuns e que tenham semelhanças. O cotidiano revela-se, então, como um modo emancipatório pelo qual o homem tem de pensar as suas ações e ver nelas os elementos de singularidade que as tornam únicas, como únicas são as experiências, que, segundo Larrosa (2002), nunca se repetem.

Assim, o cotidiano é aquilo que nos é dado a conhecer e nos leva a produzir experiências, a cada dia, sendo nele que a nossa história de formação vai sendo constituída. O que há de presente no cotidiano é o elemento que nos move pela constituição de nós mesmos, levando em consideração o que intimamente nos prende a este cotidiano. Nesta mesma direção, Oliveira e Sgarbi (2008) defendem uma concepção de cotidiano para além da noção do que chamam de espaçotempo do conhecimento de senso comum. Para eles:

Os processos de criação de conhecimento científico são, portanto, todos eles processos sociais nos quais as estruturas sociais, as relações de poder, as circunstâncias do momento, as possibilidades da competên- 
cia científica e da vida pessoal dos pesquisadores, os espaçostempos nos quais tudo será pensado, vivido, e produzido se enredam, não permitindo mais que creiamos nem na neutralidade do conhecimento científico, nem nas fronteiras que a modernidade pretendeu marcar entre essas diferentes instâncias e dimensões. (OLIVEIRA; SGARBI, 2008, p. 72)

A partir deste entendimento, os referidos autores defendem que o cotidiano não pode mais ser compreendido por noções de espaço e de tempo que estejam dissociadas dos espaços de produção e, muito menos, sejam entendidas como o lócus da repetição de ações do dia a dia, como se o cotidiano fosse o mero resultado da produção do conhecimento de senso comum. Na contramão dessa perspectiva, os autores nos mostram que o cotidiano assume uma relevante dimensão de lócus de vários entrecruzamentos dos diferentes espaços e tempos da vida social. Concluem, em seu raciocínio, que o cotidiano "é o espaçotempo da complexidade da vida social, na qual se inscreve toda produção de conhecimento e práticas científicas, sociais, grupais, individuais" (OLIVEIRA; SGARBI, 2008, p. 72).

Ao tratar da não vivência da escola no curso de Letras, Jerusa entende o PIBID como um espaço de produção de experiências que a ajudam a compreender os sentidos de sua formação, a partir do cotidiano escolar. As aprendizagens ocorrem em um ato relacional, que faz emergir os sentidos do Programa a partir da consideração que, uma vez inserido na licenciatura, o PIBID supre a carência formativa do professor, que não teve, fora do Programa, a mesma vivência do cotidiano escolar que ele oportuniza. Assim nos diz a bolsista:

\begin{abstract}
O PIBID está me ajudando muito, porque o que eu não vivi na sala de aula, durante o curso de Letras, eu agora estou vivendo e experimentando. Aprendo a ser professora tanto quanto com a professora da escola como também vendo os alunos. Então, para mim, está sendo muito gratificante e eu estou aprendendo com tudo isso. Porque essa lacuna, que ficou em aberto, eu acredito que esteja assim suprido um pouco no PIBID. (Jerusa, entrevista narrativa, 2016)
\end{abstract}

De modo semelhante ao que entendem Alves e Garcia (2000), o cotidiano escolar permite que as teorias aprendidas na formação em licenciatura sejam atualizadas, outras vezes confirmadas, em alguns ca- 
sos, não dando conta do que acontece, e tudo isso provoca a busca de outras explicações teóricas e de outras formas de pensar sobre o que ocorre entre alunos e professores, pois estes têm a função de ensinar e aqueles de aprender. No caso dos professores em formação, o cotidiano da escola os ajuda a pensar as teorias que aprendem na universidade e a desenvolvê-las a partir daquilo que o conhecimento da escola lhes faculta. Nesse contexto, o conhecimento de como a escola se organiza e funciona faz o licenciando elaborar outra visão sobre esse espaço, que deixa de ser visto em uma ótica de aluno e passa a ser visto por um professor em formação, o que instaura um processo identitário que faz cada compreender como a docência se constitui experiencialmente no contexto de seu desenvolvimento na escola.

A participação em ações e práticas organizativas do trabalho docente é a forma que Karine encontra de se reapropriar do espaço organizado pelas técnicas da produção sociocultural da escola, que sempre teve enquanto foi aluna, mas que, agora, passa a ocupar um novo papel, o de professor em formação. Isso implica dizer que o cotidiano escolar se redimensiona para a bolsista como um outro modo de conceber a docência em suas características formativas. Instaura-se uma nova arte de fazer e de compreender a escola e o seu cotidiano, que se origina de percepções e observações evidenciadas pela preocupação que passa a ter com os aspectos do baixo desempenho.

Isso sugere que a bolsista passa a desenvolver uma forma de pensar sobre como o professor lida com essas situações e dilemas da educação. Esse é um movimento reflexivo, que não acontece em uma lógica repetitiva, como se assim fosse o cotidiano da escola. As realidades vão sendo tecidas segundo a ótica experiencial de estar inserido no cotidiano escolar pelo PIBID, o que significa ser professor em fase de formação, mas em uma atuação que precisa se inserir no cotidiano da escola, enfrentando, pensando, criando e modificando, cada um a seu jeito, os sentidos sobre o ser docente no cotidiano escolar e de como nesse âmbito a ideia do ser professor se constitui em uma cultura marcada pelo processo histórico de pluralização dos sentidos da docência.

Em um trecho de seu memorial, Karine nos fala sobre os sentidos de estar no PIBID. Assim ela reflete:

Tenho tal visão porque estar no PIBID é viver a escola. Conheço as turmas que trabalho como a palma da 
mão. Também tem atividades que, vez ou outra, não saem como o planejado, mas a interação e o desenvolvimento em sala é diferente. É como se nas turmas que estou no PIBID eu me sentisse, realmente, parte do cotidiano escolar. (Karine, memorial de formação, 2016)

Estar no PIBID significa viver a escola, em seus aspectos organizativos, sobretudo relativos ao desenvolvimento de práticas do ser docente. Pensar nessa lógica é pensar que esse cotidiano faculta, dentre tantas coisas, a preocupação de como o ensino de fato acontece na escola e como dele se produzem reflexões e novas experiências, tendo em vista desenvolver outras formas de ensinar e de pensar, ou seja, como o ensino provoca o licenciando a reviver experiências sobre os diferentes modos de fazer a iniciação à docência, no cotidiano escolar. A respeito do cotidiano de ensino, Jonas assim pondera:

Outro aspecto que tem me despertado interesse é o fato de o PIBID e a vivência com a escola impulsionarem em mim verdadeira preocupação com o ensino em sala de aula. Depois do PIBID, minha visão acerca do ensino ficou mais sensível [...]. Nesse sentido, percebo-me nesse processo de busca de práticas pedagógicas para o meu futuro ofício de docência e assim vou entendendo esse funcionamento como um mecanismo de amadurecimento, que não me deixa pronto para encarar os desafios da profissão, mas que, certamente, me instrumentaliza para enfrentar as dificuldades do ser professor com mais capacidade e segurança. (Jonas, entrevista narrativa, 2016)

O ensino é entendido como base do ofício docente. Em sua compreensão, o licenciando utiliza-se de expressões para demarcar o trabalho docente, tais como: ofício, práticas pedagógicas, ensino e docência. Isso parece evidenciar o modo como ele compreende o trabalho docente e o vê em diferentes abordagens e perspectivas. Se para alguns isso pode ser indicativo de confusão, pensamos que seja o resultado de um processo de reflexão e de aprendizagem em que o licenciando vai se apropriando de termos que têm direta relação com a profissão docente. $O$ curioso a se observar é que a consciência crescente de Jonas sobre a profissão docente vai lhe fornecendo pistas e formas de pensar em si próprio, como um sujeito que está em plena formação e que precisa compreender os diferentes atributos que tem 
um professor. Com isso, segundo suas próprias palavras, terá condições de desenvolver uma atividade docente que seja fruto das dimensões de realidade onde ela acontece. Isso implica o entendimento de que os índices de qualidade do trabalho do professor são aferidos pela apropriação que este faz de experiências e da própria produção de experiências, em sala de aula, em uma dimensão real e não fictícia. Não se trata de simular o ensino, mas de se inserir em um cotidiano em que se pode evidenciar e experienciar o ensino nos contextos reais de seu desenvolvimento.

Todo esse movimento formativo e reflexivo sugere haver, como nos diz Jonas, um amadurecimento da compreensão sobre a docência. Esse fato não pretende tornar o licenciando apto, capaz de enfrentar os desafios da profissão, mas lhe permite desenvolver as condições mínimas necessárias à lida com as dificuldades inerentes à profissão docente.

Segundo essa lógica, vemos que o PIBID insere o licenciando no cotidiano escolar para que ele desenvolva a aprendizagem do ser docente. Nessa aprendizagem e nos processos de identificação com a profissão, entendemos a produção identitária. Mas, ao ter uma visão mais sensível do ensino, a partir do Programa, em dimensões reais do/no cotidiano escolar. Para Jonas, essas dimensões passam a ter significado, revelando que os processos de aprendizagem, tanto para o professor em formação quanto para os alunos da escola básica, precisam ter sentido para aquele que aprende. Assim, a aprendizagem deve ter uma relação direta com aquilo que já se sabe de algo e como esse algo vai ser ressignificado a partir do que se aprende (AUSUBEL, 1982).

Para este autor, a aprendizagem significativa é aquela em que ideias expressas simbolicamente interagem de maneira substantiva e não-arbitrária com aquilo que o aprendiz já sabe. Segundo Ausubel (1982) de maneira substantiva quer dizer não-literal, não ao pé-da-letra. Por isso a aprendizagem significativa é tecida e constituída na experiência e reflexão do próprio sujeito, como faz Jonas no Programa. O autor também explica o termo não-arbitrária, mostrando que isto significa que a interação não é com qualquer ideia prévia, mas sim com algum conhecimento especificamente relevante já existente na estrutura cognitiva do sujeito que aprende. E neste caso o conhecimento pré-existente para o licenciando é aquilo que ele já sabe sobre o que significa a profissão docente e como ela é desenvolvida no cotidiano escolar. 
Trazendo à tona os sentidos da docência, a partir de sua trajetória de vida, do processo formativo na licenciatura e, nele, as experiências do cotidiano escolar por meio do Programa, o bolsista é mobilizado por uma aprendizagem sobre a docência que lhe permite articular os conhecimentos oriundos de sua formação ao contexto prático da sala de aula. Nesse sentido, a aprendizagem sobre a docência gera um lugar de significação sobre as "artes do fazer" docente na escola, que, dentre tantas coisas, precisa levar em consideração as razões e os modos deste fazer.

Assim é que, como pensa Josso (2004), entendemos que a narrativa (auto)biográfica se instaura como uma forma de dizer a nós mesmos os modos como nos apropriamos do que já conhecemos para produzir novas aprendizagens. Da mesma forma, segundo Ausubel (1982), estas apropriações passam a ser significativas por adquirirem um novo sentido, a partir do que já se sabia. A experiência produzida no cotidiano ganha, então, centralidade nesse processo, que, no caso de Jonas, é vista como formadora, um divisor de águas que, desde o cotidiano escolar, Ihe apresenta a constituição da profissão docente em suas dimensões reais. Assim:

\begin{abstract}
Começamos a perceber que o que faz a experiência formadora é uma aprendizagem que articula, hierarquicamente: saber-fazer e conhecimentos, funcionalidade e significação, técnicas e valores num espaço-tempo que oferece uma oportunidade de uma presença para si e para a situação, por meio de uma pluralidade de registros. Se a abordagem biográfica é um meio para observar um aspecto central das situações educativas, é porque ela permite uma interrogação das representações do saber-fazer e dos referenciais que servem para descrever e compreender a si mesmo no seu ambiente natural. Para perceber como essa formação se processa, é necessário aprender, pela experiência direta, a observar essas experiências das quais podemos dizer, com mais ou menos rigor, em que elas foram formadoras. (JOSSO, 2004, p. 39)
\end{abstract}

A narrativa que Jonas constrói revela a compreensão de suas experiências formadoras no PIBID, mostrando para si mesmo de que maneira o cotidiano escolar o faz ter clareza sobre a formação para a docência, constituindo-se a partir do que ele já guardava em suas lembranças sobre o ser professor. Nesse esquema reflexivo, a condição biográfica faz com que ele perceba o modo como elabora questões sobre a profissão 
docente, revelando como o saber-fazer se apresenta em conhecimentos que vão sendo ressignificados, no cotidiano escolar, em um processo significativo de aprendizagem, conforme já dito, elaborado por ideias expressas simbolicamente que interagem, de maneira substantiva e não-arbitrária, com aquilo que o aprendiz já sabe. Esse esquema, conforme nos assevera Josso (2004), é compreendido como a forma que o sujeito tem de produzir experiências, em seu ambiente natural de formação, mas que carrega em si o poder da observação de tantas outras vivências que o fazem atribuir novos sentidos e significados às experiências, gerando a concepção de que essas experiências são formadoras. $\mathrm{E}$ assim o são, pois desenvolvem um processo de aprendizagem que, para quem aprende (neste caso, os licenciando), é significativo, na medida em que são experiências formadoras, pois tecidas em uma dimensão da subjetividade do sujeito, bem como em numa temporalidade que se adapta aos ritmos de compreensão fenomenológica da docência, que cada um é capaz de produzir, em seus percursos formativos, logo em sua trajetória de vida e formação.

A posição de criticidade também surge como um elemento de identificação do papel do professor, que se desenvolve como apreensão dos contextos, reais e naturais (JOSSO, 2004), em que a formação acontece. Neste caso, é no cotidiano escolar em que se produzem as experiências, que, para o bolsista, são vivenciadas na escola, ao longo de sua participação no Programa. Essa compreensão revela que o PIBID cumpre um papel formador e, também motivador, a partir de experiências vivenciadas no cotidiano escolar que demandam a produção de aprendizagem significativa sobre a profissão docente.

\section{Considerações}

O estudo mostrou que a abordagem (auto)biográfica foi relevante para que se pudesse compreender que o ato de narrar sua própria história de formação constitui-se para os licenciandos como um momento em que a reflexão se instaurou como forma do sujeito compreender a si mesmo e ao outro, na relação que se estabelece na e pela linguagem. Assim, as entrevistas, tanto como os memoriais, foram significativas para que as experiências de formação no PIBID pudessem ser registradas, desvelando os sentidos que atribuem a cada experiência. A narrativa demarcou um lugar onde o sujeito organizou sua compreensão do 
percurso formativo no PIBID, em um constante movimento de reflexão e autorreflexão, focalizando as experiências produzidas no cotidiano e na própria iniciação, e revelando como todo esse percurso tem relação com a produção de sua identidade docente.

O trabalho revelou, ainda, que, no cenário do PIBID, o conceito de formação é concebido epistemologicamente como um movimento reflexivo de compreensão da profissão docente, sendo entendido a partir da inserção dos licenciandos no contexto da escola e da apreensão das dinâmicas do trabalho docente, estruturado em práticas organizativas que levam em consideração a escola e o seu cotidiano. Nesta direção, o estudo evidenciou que a formação é um processo gerado pelo constante movimento de construção e reconstrução das aprendizagens pessoais e profissionais, que se fazem e refazem nas experiências do sujeito. Nessa lógica, os processos formativos se relacionam com a construção da identidade, em uma dimensão de consciência e autoconsciência que permite ao sujeito entender e compreender a sua trajetória de vida e formação.

Por meio do PIBID foi possível fazer um movimento de reflexão sobre a docência, como forma de se assumir a ideia de que as experiências precisam ser narradas e entendidas, a partir das ações que cada sujeito faz ao falar de si e de como pensa e age no Programa. Essa possibilidade se evidenciou, dentre outras razões, porque as narrativas universalizam experiências, revelando as influências que são frutos das relações estabelecidas no âmbito da prática escolar. Foi a partir da socialização, na escola e em seu cotidiano, que o licenciando no PIBID foi construindo e percebendo como as experiências do ser professor emergiram como possibilidade de reflexão e constituição dos processos identitários que tiveram, no Programa, uma motivação pela inserção no cotidiano escolar. Esse esquema reflexivo sugere ser o PIBID um modo epistemológico de desenvolver aprendizagem da docência, em que a inserção no cotidiano escolar assume papel relevante no processo de formação inicial de professores.

\section{Referências}

ALVES, Nilda; GARCIA, Regina Leite et al. (Orgs.) A invenção da escola a cada dia. Rio de Janeiro: DP\&A, 2000. 
AUSUBEL, David P. A aprendizagem significativa: a teoria de David Ausubel. São Paulo: Moraes, 1982.

BRASIL. Ministério da Educação - Proposta de Diretrizes para a Formação de Professores da Educação Básica em Nível Superior. Parecer CNE/CP no 009/2001 e Resolução CNE/CP n 1/2002 Brasília, maio de 2002.

CERTEAU, Michel de. A invenção do cotidiano: 1. Artes de fazer. Petrópolis, RJ: Vozes, 1994.

FERRAROTTI, Franco. Sobre a autonomia do método biográfico. In: NÓVOA, António; FINGER, Matthias. (Orgs.). 0 método (auto)biográfico e a formação. Lisboa: Ministério da Saúde/Depart. de Recursos Humanos da Saúde/Centro de Formação e Aperfeiçoamento Profissional, 1988. p. 17-34.

JOSSO, Marie-Christine. Experiências de vida e formação. São Paulo: Cortez, 2004.

LARROSA, Jorge. Notas sobre a experiência e o saber da experiência. Tradução de João Wanderley Geraldi. Revista Brasileira de Educação, n. 19, p. 01-11, 2002.

NÓVOA, António; FINGER, Matthias. (Orgs.). 0 método (auto)biográfico e a formação. Natal: EDUFRN; São Paulo: Paulus, 2010.

NÓVOA, António. Nada substitui um bom professor: propostas para uma revolução no campo da formação de professores. In: GATTI, Bernadete Angelina et al. (Orgs.). Por uma política nacional de formação de professores. São Paulo: Unesp, 2013. p. 189-203.

OLIVEIRA, Inês Barbosa; SGARBI, Paulo. Estudos do cotidiano e educação. Belo Horizonte: Autêntica, 2008.

OLIVEIRA, Inês Barbosa. Currículos praticados em tempos de globalização: o cotidiano escolar e seus condicionantes na criação de alternativas emancipatórias. In: OLIVEIRA, Inês Barbosa. (Org.) Práticas cotidianas e emancipação social: do invisível ao possível. Petrópolis, RJ: DP et Alii, 2010.

SILVA, Fabrício Oliveira da. Formação docente no PIBID:Temporalidades, Trajetórias e Constituição identitária. 2017. 220f. Tese (Doutorado em 
Educação) Faculdade de Educação, Universidade do Estado da Bahia, Salvador, 2017.

Recebido: Outubro/ 2018

Aceito: Março/ 2019 